\title{
CDNA-AFLP NA IDENTIFICAÇÃO DE GENES RELACIONADOS A QUALIDADE FISIOLÓGICA ${ }^{1}$
}

\author{
LILIANE MARCIA MERTZ², FERNANDO AUGUSTO HENNING², PAULO DEJALMA ZIMMER²
}

\begin{abstract}
RESUMO - Alguns trabalhos têm evidenciado a existência de genótipos de soja contrastantes para qualidade fisiológica de semente. Tais diferenças existem em virtude da presença de sementes com total ou parcial impermeabilidade do tegumento à água, o que as tornam menos susceptíveis aos danos mecânicos, as adversidades climáticas e a deterioração por umidade. A característica de tegumento semi-permeável pode ser incorporada às cultivares de alta produção por meio dos programas de melhoramento. No entanto, há necessidade de caracterizar os genes ou as regiões genômicas envolvidas com esta característica. Nesse contexto, ferramentas da biologia molecular, como a técnica de cDNA-AFLP, podem auxiliar a identificação de genes relacionados a qualidade fisiológica de sementes. O objetivo desse estudo foi verificar a eficácia da técnica de cDNA-AFLP, na obtenção de fragmentos de genes diferencialmente expressos entre tegumentos de sementes de soja com permeabilidade contrastante. Sementes provenientes dos genótipos CD-202 (tegumento amarelo, permeável e susceptível a deterioração) e TP (tegumento preto, semi-permeável e resistente a deterioração) foram cultivadas em casa-de-vegetação, sob condições homogêneas. Realizou-se a coleta das sementes em diferentes estágios de desenvolvimento $(25,30,35,40$ e 55 dias após a antese). Procedeu-se à extração do RNA total utilizando-se três métodos, sendo o reagente Pure Link Plant RNA o mais eficiente. Para obtenção do cDNA dupla fita utilizou-se o kit Double Stranded cDNA Synthesis. A partir do cDNA obtido, aplicou-se a técnica de AFLP testando-se um total de 64 combinações de primers. Foram obtidos 47 fragmentos de cDNA diferencialmente expressos entre os tegumentos de sementes dos dois genótipos, os quais poderão ter suas funções reveladas pelo sequenciamento e análise in sílico. De acordo com os resultados obtidos, a técnica de cDNAAFLP demonstra ser uma alternativa promissora para estudos que visem à identificação de genes relacionados a qualidade de sementes.
\end{abstract}

Termos para indexação: permeabilidade do tegumento, marcador molecular, Glycine max.

\section{cDNA-AFLP TECHNIQUE TO GENES IDENTIFICATION INTERESTING TO PHYSIOLOGICAL QUALITY}

\begin{abstract}
Some studies have reported the existence of contrasting soybean genotypes for seed physiological quality. Differences such as presence of seeds with total or partial impermeability for water absorption through the seedcoat make them less susceptible to mechanical damage, adverse weather and deterioration. The semi-permeable seed coat trait can be used in soybean crop breeding programs to be incorporated in genotypes with high production. However, is necessary to characterize genes involved with the trait. Molecular biology tools, such as the cDNA-AFLP technique, can be used to identify genes involved in seed physiological quality. The objective of this study was to evaluate
\end{abstract}

${ }^{1}$ Submetido em 20/02/2008. Aceito para publicação em 24/07/2008.

${ }^{2}$ Eng. Agr., Alunos do Programa de Pós-Graduação em C\&T de Sementes

- FAEM/UFPel. e-mail: lilianemertz@yahoo.com.br. CEP: 96010-900
Caixa postal 354, Pelotas-RS, Brasil.

${ }^{3}$ Eng. Agr., Dr. Prof. do Departamento de Fitotecnia/ UFPel., e-mail:djzimmer@ufpel.edu.br. 
the efficacy of the cDNA-AFLP technique to obtain gene fragments differently expressed among soybean seedcoats with contrasting permeability. Seeds from two genotypes, CD-202 (susceptible to deterioration and permeable yellow coat) and TP (resistant to deterioration and semi-permeable black coat) were produced in greenhouse under homogeneous conditions. Seeds were harvested at different times $(25,30,35,40$ e 55 days after anthesis). The total RNA was extracted using Pure Link Plant RNA reagent. The Double Stranded cDNA Synthesis Kit was used to obtain cDNA double strand. The AFLP technique was applied and 64 primer combinations were tested. This tool permitted the identification of 47 gene fragments differently expressed among coats from the two genotypes and was shown to be an efficient alternative to studies related to the identification of genes involved in seed quality.

Index terms: coat permeability, molecular markers, Glycine max.

\section{INTRODUÇÃO}

Entre os genótipos de soja existe variabilidade genética quanto à qualidade fisiológica de sementes, a qual pode ser utilizada em programas de melhoramento genético. Um exemplo é a diferença quanto à resistência ao dano mecânico onde a maior tolerância tem sido relacionada ao maior teor de lignina no tegumento da semente, enquanto a resistência à deterioração no campo tem sido associada ao grau de permeabilidade do tegumento (Alvarez et al., 1997).

A semi-permeabilidade do tegumento reduz o efeito das flutuações de umidade sobre as sementes, tornando-as menos suscetíveis à deterioração a campo. Além disso, propicia maior potencial de armazenamento, maior resistência aos danos mecânicos e menor ocorrência de danos causados por percevejos (França Neto et al., 2000).

Segundo França Neto e Potts (1979), a introdução da característica semi-permeabilidade de tegumento em cultivares modernas e de boas características agronômicas, pode reduzir os índices de deterioração no campo, além de outras vantagens como aumento no potencial de armazenamento da semente, menores infestações de microorganismos e, possivelmente, menores níveis de danos causados pela trilha mecânica. Assim, há necessidade de caracterizar os genes ou as regiões genômicas envolvidas com esta característica, onde técnicas da biologia molecular podem ser utilizadas para o isolamento e a identificação de genes relacionados a permeabilidade do tegumento em sementes de soja.

As respostas biológicas são controladas pela regulação da expressão gênica. A identificação de genes expressos em um determinado tecido ou órgão, sob influência de uma determinada condição do ambiente e em um dado momento, pode facilitar a compreensão de rotas metabólicas envolvidas em processos fisiológicos de interesse, como no caso desse estudo, a permeabilidade do tegumento de sementes de soja.

Uma variedade de técnicas moleculares está disponível para a identificação e clonagem de genes diferencialmente expressos, incluindo differential display e RNAfingerprinting. Esses métodos apresentam, entretanto, limitações tais como reprodutibilidade, dificuldade em expressar mensagens muito raras e geração de falsos positivos. Esses problemas surgem primeiramente devido ao uso de primers com oligonucleotídeos arbitrários e pela necessidade de temperaturas de anelamento relativamente baixas para obter os produtos de amplificação (Bachem et al., 1998).

O método do cDNA-AFLP supera amplamente tais limitações e possibilita uma simples e rápida verificação da identidade da banda. Além disso, permite a avaliação sistemática de quase todos os transcritos em um dado sistema biológico utilizando pequenas quantidades de material inicial (Bachem et al., 1998).

A síntese do cDNA é realizada pela da ação da enzima transcriptase reversa, uma enzima de origem viral que tem a capacidade de produzir uma molécula de DNA dupla fita a partir da cópia de uma molécula de RNA mensageiro. Ou seja, como o próprio nome diz, a transcriptase reversa faz o caminho contrário daquele percorrido pela RNA polimerase, a qual, a partir de uma molécula dupla fita de DNA, produz o RNA.

Presumindo que as diferenças estruturais existentes entre tegumentos de sementes de soja de distintos genótipos sejam responsáveis por uma maior ou menor susceptibilidade a deterioração de sementes, e, que tais diferenças decorram de genes diferencialmente expressos, com o auxílio da técnica 
de cDNA-AFLP talvez seja possível identificar fragmentos de genes relacionados ao tegumento e a qualidade fisiológica das sementes.

Esse trabalho teve por objetivo verificar a eficácia da técnica de cDNA-AFLP, na obtenção de fragmentos de cDNA diferencialmente expressos entre tegumentos de sementes de soja com permeabilidade contrastante.

\section{MATERIAL E MÉTODOS}

- Obtenção do material vegetal: Nesse estudo foram utilizados dois genótipos de soja contrastantes para as características de tegumento, CD 202 (tegumento amarelo, permeável e considerado suscetível à deterioração) e TP (tegumento preto, semi-permeável - considerado mais resistente à deterioração).

O experimento foi instalado em casa-de-vegetação, no dia 17 de novembro de 2005. As plantas foram cultivadas em condições homogêneas em vasos de plástico. Foram semeadas cinco sementes por vaso e após a emergência realizou-se o raleio deixando-se apenas duas plântulas por vaso.

Para cada genótipo foram utilizadas quatro repetições de duas plantas, resultando em um total de dezesseis vasos por genótipo.

A partir da antese iniciou-se a marcação de flores para que todas as sementes amostradas estivessem no mesmo estádio de desenvolvimento. Foram realizadas sete amostragens em intervalos de cinco dias $(25,30,35,40,45,50,55$ dias após a antese). Assim que colhidas, as sementes foram colocadas imediatamente no gelo e transportadas até o Laboratório de Biossementes (FAEM/UFPel), onde os tegumentos foram separados das sementes com auxílio de lâminas esterilizadas, tomando-se o cuidado de manter o tecido vegetal puro, ou seja, sem nenhum resquício de cotilédone ou qualquer outro tecido que não fosse tegumento. Esse material permaneceu estocado em ultra freezer a $-80^{\circ} \mathrm{C}$ até o momento da extração do RNA.

\section{- Obtenção dos fragmentos de cDNA-AFLP:}

A técnica para obtenção dos fragmentos consistiu nas etapas de extração do RNA total, obtenção do cDNA dupla fita, e, avaliação do polimorfismo genético pela técnica de cDNA-AFLP.

Para extração do RNA total dos tegumentos das sementes de soja, foram testados três protocolos de extração. No primeiro foi utilizando o reagente Trizol (Invitrogen ${ }^{\circledR}$ ) seguindo as recomendações do fabricante, no segundo, o protocolo proposto por Chang et al. (1993) adaptado para 100mg de tecido vegetal, e no terceiro utilizando o reagente Pure Link Plant RNA (Invitrogen $\left.{ }^{\circledR}\right)$, seguindo as recomendações de uso.

Para cada um dos protocolos testados, realizou-se primeiramente o tratamento de todas as vidrarias, cadinhos, pistilos e demais utensílios necessários com água contendo $0,01 \%$ de dietilpirocarbonato $\left(\mathrm{H}_{2} \mathrm{O}_{\text {DEPC }}\right)$, para evitar a ação de enzimas que degradam o RNA (RNases).

Após o término da extração analisou-se a pureza e a integridade do RNA total extraído pela de análise de absorbância (260/280nm) e eletroforese em gel de agarose 1,5\% (Sambrook et al., 2001).

Cabe ressaltar que a extração do RNA foi realizada separadamente para cada época de amostragem. No momento da síntese do cDNA dupla fita, essas amostras de RNA total foram misturadas e homogeneizadas, formando uma mistura de RNA que foi utilizada para síntese do cDNA.

O cDNA dupla fita foi sintetizado utilizando o kit SuperScript Double Stranded cDNA Synthesis (Invitrogen ${ }^{\circledR}$ ), seguindo as recomendações de uso do produto. Após a síntese, o cDNA foi quantificado pela de análise de absorbância (260/280nm) e visualizado em eletroforese de gel de agarose 1,5\% (Sambrook et al., 2001).

Ao cDNA obtido, aplicou-se a técnica de AFLP conforme metodologia descrita por Vos et al. (1995). Foram realizadas as etapas de digestão do cDNA com enzimas de restrição (EcoR I e Mse I), ligação de adaptadores específicos aos terminais dos fragmentos de cDNA gerados pela clivagem, pré-amplificação dos fragmentos de restrição utilizando os primers EcoR I +A e Mse I +C , amplificação seletiva de fragmentos utilizando três bases seletivas e eletroforese dos fragmentos de cDNA amplificados em gel de poliacrilamida. Para execução dessa técnica utilizou-se o AFLP Starter Primer Kit (Invitrogen ${ }^{\circledR}$ ), seguindo recomendações do fabricante. Foram testadas as 64 combinações de primers disponíveis no kit.

Os fragmentos de cDNA diferencialmente expressos, foram visualizados em gel de poliacrilamida $(5 \%$ de concentração) o qual foi revelado com nitrato de prata (Creste, 2001).

\section{RESULTADOS E DISCUSSÃO}

os requisitos fundamentais para obter sucesso com a técnica de cDNA-AFLP, consiste na obtenção de RNA com qualidade e em quantidade suficiente. O método do Trizol é frequentemente utilizado, sendo recomendado para extração de RNA total de tecidos e células de humanos, plantas, 
animais e bactérias. Esse método, entretanto, foi eficiente apenas para extração de RNA dos tegumentos provenientes do genótipo CD-202 enquanto que para o genótipo TP esse protocolo não funcionou (Figura $1 \mathrm{~A}$ e B).
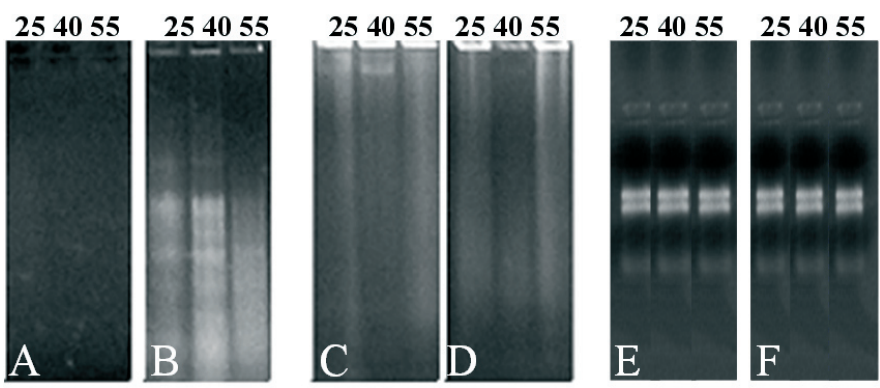

FIGURA 1. RNA total em gel de agarose $1,5 \%$, isolado de tegumentos de sementes de soja (Glycine max) em três estádios de desenvolvimento (25, 40 e 55 dias após a antese), utilizando três protocolos de extração (Trizol (Invitrogen); Chang et al. (1993); Pure Link Plant RNA (Invitrogen)). A - Genótipo TP (tegumento preto) Trizol; B - Genótipo CD-202 Trizol; C- Genótipo TP Chang; D- Genótipo CD202 Chang; E- Genótipo TP Pure Link Plant RNA; F- Genótipo CD-202 Pure Link Plant RNA.

Com base no estudo de Todd e Vodkin (1993), foram testados outros protocolos de extração recomendados para tecidos que possuem alta quantidade de fenóis, como o protocolo estabelecido por Chang et al. (1993). Com este protocolo RNA de ambos os genótipos foi extraído, porém, em quantidades insuficientes (Figura $1 \mathrm{C}$ e D).

Estudos demonstram que a dificuldade de extrair RNA de tecidos como tegumento preto, deve-se à presença de pró-antocianinas e antocianinas, existentes em tegumentos de sementes de soja de coloração preta ou marrom, as quais interagem com o RNA formando um complexo que altera o espectro de absorbância, a migração do RNA e a capacidade de hibridização do RNA com DNA (Todd e Vodkin, 1993).

A utilização do terceiro método, no qual se utilizou o reagente Pure Link Plant RNA Reagent, foi extremamente eficiente para extração de RNA total de tegumentos em ambos os genótipos, sendo que, a quantidade de RNA total extraído por esse método foi bem superior em relação aos demais protocolos testados (Figura $1 \mathrm{E}$ e F). Este reagente é recomendado para isolamento de RNA total de alta qualidade, especialmente de tecidos que apresentam alto conteúdo de polifenóis

$\mathrm{Na}$ análise de absorbância, realizada em espectrofotômetro (Tabela 1), os valores da relação a $260 / 280 \mathrm{~nm}$ variaram entre 1.93 e 2.06 , o que indica um RNA de alta pureza.

TABELA 1. Absorbância em espectofotomêtro (260 $1280 \mathrm{~nm})$, de amostras de RNA total extraído de tegumentos de sementes de soja provenientes dos genótipos TP (tegumento preto) e CD-202 (tegumento amarelo), utilizando o reagente Pure Link Plant RNA (Invitrogen), coletados em diferentes estádios de desenvolvimento. Pelotas-RS, 2006.

\begin{tabular}{lcc}
\hline \multicolumn{1}{c}{ Genótipo } & Dias após a antese & $\mathrm{A}_{260 / 280}$ \\
\hline Tegumento Preto & 25 & 2.03 \\
Tegumento Preto & 30 & 1.98 \\
Tegumento Preto & 35 & 2.00 \\
Tegumento Preto & 40 & 2.04 \\
Tegumento Preto & 45 & 2.03 \\
Tegumento Preto & 50 & 1.99 \\
Tegumento Preto & 55 & 1.95 \\
\hline Tegumento Amarelo & 25 & 1.93 \\
Tegumento Amarelo & 30 & 2.00 \\
Tegumento Amarelo & 35 & 2.06 \\
Tegumento Amarelo & 40 & 1.99 \\
Tegumento Amarelo & 45 & 1.93 \\
Tegumento Amarelo & 50 & 1.99 \\
Tegumento Amarelo & 55 & 2.01 \\
\hline
\end{tabular}

Na figura 2 estão apresentados os resultados obtidos pela eletroforese em gel de poliacrilamida de três dos 64 pares de primers testados. Os fragmentos selecionados foram os que se apresentaram diferencialmente expressos entre os tegumentos dos dois genótipos, os quais estão indicados na figura por setas.

Comparando-se o padrão de bandas obtidas com a primeira combinação de primers, EcoRI-AAG/MseI-CTC, é possível observar a presença de sete bandas polimórficas entre os dois genótipos, quatro no genótipo TP e três no genótipo CD-202. Já a segunda combinação de primers testada, EcoRI-ACA/MseI-CTT, apesar de ter gerado um bom padrão de bandas, não apresentou nenhum fragmento 
de cDNA diferencialmente expresso. A terceira combinação, EcoRI-AGG/MseI-CTC, possibilitou a seleção de quatro fragmentos polimórficos no genótipo CD-202 (Figura 2).

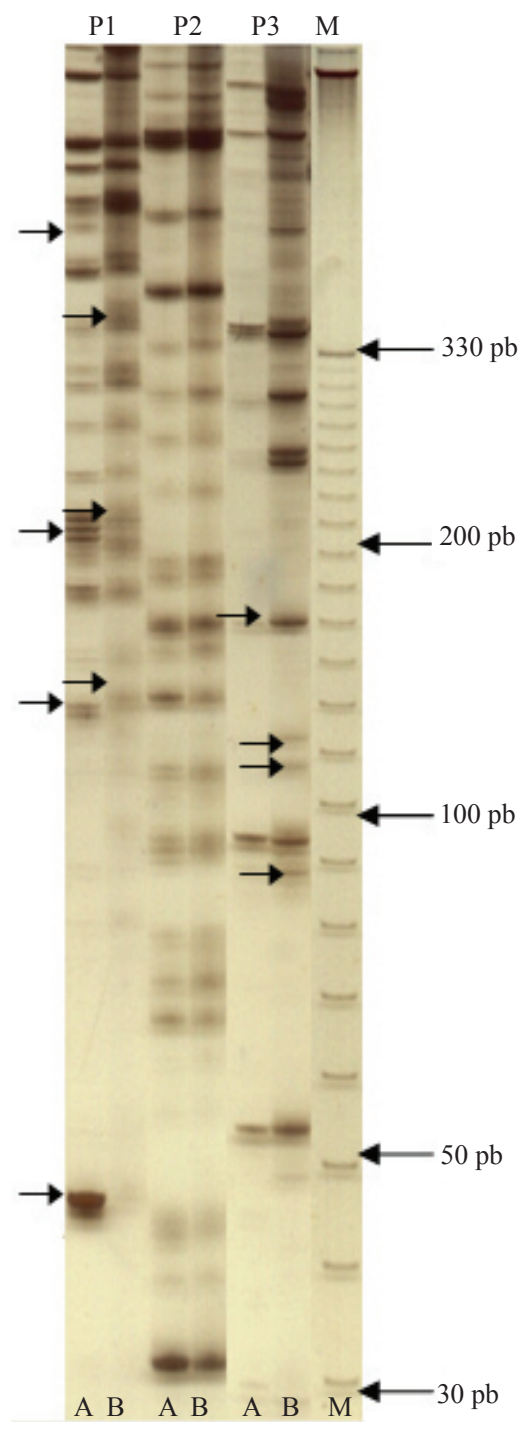

FIGURA 2. Gel de poliacrilamida $5 \%$ de fragmentos de cDNA-AFLP, obtido a partir de tegumentos de sementes de soja (Glycine max) dos genótipos TP e CD202. (A) genótipo com tegumento preto e (B) genótipo CD-202, utilizando três diferentes combinações de primers (P1-EcoRI-AAG/MseI-CTC, P2EcoRI-ACA/MseI-CTT e P3-EcoRI-AGG/ MseI-CTC, M-30-330 DNA ladder).
Dentre as 64 combinações de primers, 36 não geraram nenhum fragmento diferencialmente expresso. Algumas por não apresentarem polimorfismo, e outras por não permitirem uma amplificação adequada, o que levaria a um processo de seleção subjetivo. Entretanto, com as demais combinações testadas, foi possível identificar um total de 47 bandas polimórficas, o que pode ser considerado uma quantidade satisfatória. Esses fragmentos de genes são promissores para o desenvolvimento de marcadores relacionados a características desejáveis do tegumento.

O tamanho dos fragmentos selecionados foi variável. Foram obtidos fragmentos com mais de $330 \mathrm{pb}$ (pares de bases) até fragmentos menores, em torno de $50 \mathrm{pb}$ (Figura 2).

Aoki et al. (2005) utilizaram a técnica de cDNA-AFLP para a identificação de genes relacionados à resistência ao estresse salino em soja. Esses pesquisadores obtiveram resultados positivos, obtendo uma grande quantidade de fragmentos de cDNA, o que permitiu o isolamento e a clonagem de genes relacionados ao caráter de interesse.

Com o sequenciamento dos fragmentos de genes obtidos e posterior análise in silico, será possível identificar genes relacionados a características do tegumento, o que, auxiliará no entendimento dos processos fisiológicos envolvidos com a qualidade fisiológica de sementes de soja. Além disso, a caracterização desses fragmentos pode permitir a construção de marcadores moleculares para seleção assistida em programas de melhoramento, o que resultará em maior rapidez e eficiência no desenvolvimento de variedades em que o fator qualidade de sementes apresente prioridade.

\section{CONCLUSÃO}

A técnica de cDNA-AFLP é eficiente na identificação de genes expressos, pois permitiu a obtenção de 47 fragmentos de cDNA diferencialmente expressos entre os tegumentos de sementes de soja dos genótipos CD-202 e TP.

\section{REFERÊNCIAS}

ALVAREZ, P.J.C. Relationship between soybean seed coat lignin content and resistance to mechanical damage. Seed Science \& Technology, v.25, p.209-214, 1997.

AOKI, A.; KANEGAMI, A.; MIHARA, M.; KOJIMA, T.; SHIRAIWA, M.; TAKAHARA, H. Molecular cloning and characterization of a novel soybean gene encoding a leucinezipper-like protein induced to salt stress. Science Direct, v.356, p.135-145, 2005. 
BACHEM, C.W.; OOMEN, R.J.F.; VISSER, R.G. Transcript imaging with cDNA-AFLP: a step-by-step protocol. Plant Molecular Biology Reporter, v.16, p.157-173, 1998.

CHANG, S.; PURYEAR, J.; CAIRNEY, J. A simple and efficient method for isolating RNA from pine trees. Plant Molecular Biology Reporter, v.11, p.113-116, 1993.

CRESTE, S.; TULMANN-NETO, A.; FIGUEIRA, A. Detection of single sequence repeat polymorphisms in denaturing polyacrylamide sequencing gels by silver staining. Plant Molecular Biology Reporter, v.19, p.299306, 2001.

FRANÇA-NETO,J.B.;HENNING,A.A.;KRYZANOWSKI, F. C.; COSTA, N. P. Tecnologia de produção de sementes. In: A CULTURA da soja no Brasil. Londrina: Embrapa Soja, 2000. 1 CD - ROM.
FRANÇA NETO, J.B.; POTTS, H.C. Efeitos da colheita mecânica e da secagem artificial sobre a qualidade da semente dura em soja. Revista Brasileira de Sementes, v.1, n.2, p.64-77, 1979.

SAMBROOK, J.; RUSSEL, D. W. Molecular cloning: a laboratory manual. 3ed. Cold Spring Harbor Laboratory Press, 2001.

TODD, J. J.; VODKIN, L.O. Pigmented soybean (Glycine max) seed coats accumulate proanthocyanidins during development. Plant Physiology, v.102, p.663-670, 1993.

VOS, P.; HOGRES, R.; BLEEKER, M.; REIJANS, M.; LEE, T.; HORNES, M.; FRITJERS, A.; POT, J.; PELEMAN, J.; KUIPER, M.; ZABEU, M. AFLP: a new technique for DNA fingerprinting. Nucleic Acid Reserch, v.23, p.4407-4414, 1995. 